\title{
PLURIMIDIALIDADE NO MUNDO DIGITAL DE ALICE ATRAVÉS DO ESPELHO, DE PAULO DE MORAES
}

\section{PLURIMEDIALITY IN THE DIGITAL WORLD OF PAULO DE MORAES'S ALICE ATRAVÉS DO ESPELHO}

\author{
Mail Marques Azevedo \\ UNIANDRADE, Curitiba, Paraná, Brasil \\ mail_marques@uol.com.br
}

\begin{abstract}
Resumo: A versão digitalizada de Alice através do espelho (2014), de Paulo de Moraes, é uma mixagem de mídias que se concatenam ou superpõem, em cenas de musical com solos, coros, dança e, particularmente, animação gráfica, que movimenta a ação e fornece cenários. A cenografia utiliza-se de recursos do circo - malabarismos no trapézio, explosões inesperadas, escorregadores e cenários que despencam - e mais, de jogos de luzes e figurinos representativos dos seres do país das maravilhas. A partir do exame dos mecanismos utilizados para envolver a plateia, este artigo analisa o papel da imaginação na criação dos seres estranhos do universo de Carroll, com base no conceito de conceptual blending, proposto por Fauconnier e Turner (2003). Para os autores a imaginação é a mola propulsora da criatividade inerente aos seres humanos e o mecanismo básico na formação do pensamento.
\end{abstract}

Palavras-chave: Encenação; Plurimidialidade; Alice através do espelho; Conceptual blending

\begin{abstract}
The digital version of Paulo de Moraes's production of Alice através do espelho (2014) is a merging of connected or superposed medias such as musicals, with solo or choir singing and dancing plus, particularly, graphic animation that forwards the action and furnishes settings. The cenography uses resources of the circus - juggling, unexpected explosions, slides, crumbling settings and play with lights, besides costumes tailored to represent the strange creatures of the wonder world. Starting from the exam of the mechanisms that involve the public in the performance, this article analyzes the role of imagination in the creation of Carroll's creatures, based on Fauconnier's and Turner's (2003) argument of conceptual blending: imagination as the driving force behind human creativity and the basis for the development of human thought.
\end{abstract}

Keywords: Performance; Plurimediality; Alice através do espelho; Conceptual blending 
A encenação da peça Alice através do espelho pelo grupo Armazém Companhia de Teatro alcançou suporte digital em 2004, sob a coordenação geral do diretor Paulo de Moraes e dramaturgia de Mauricio Arruda Mendonça. A adaptação do clássico de Lewis Carroll atinge níveis de recriação textual, a que corresponde uma cenografia digna do mundo de fantasia de Alice: cenas em um escorregador ou sob um teto que ameaça desabar sobre os espectadores; malabarismos no trapézio; jogos de luzes, explosões e figurino representativo. A versão em DVD, objeto deste trabalho, é uma mixagem de mídias que se concatenam e superpõem, em cenas de musical com solos, coros e dança e, particularmente, com ênfase na animação gráfica que movimenta a ação e fornece cenários. Analisa-se na versão digital plurimidiática da peça o processo de conceptual blending na construção de personagens e do cenário do espelhotáculo de Paulo de Moraes. Para contextualizar a montagem da peça e a posterior digitalização de 2004 no âmbito das sucessivas transposições midiáticas de Alice no país das maravilhas e Através do espelho, desde sua publicação no final do século XIX, comentam-se alguns exemplos notáveis.

A criação das narrativas destinadas a distrair as três meninas da família Lidell certamente exigiu de Charles Ludwidge Dodgson riqueza de imaginação aparentemente incompatível com a figura circunspecta do professor de matemática de Oxford. O cenário rural das margens do rio, durante os famosos passeios de barco em tardes de verão, evidentemente forneceu material para a construção de espaço físico e de personagens- lebres, camundongos, flores, crisálidas e borboletas. O pensamento racional do professor de matemática, encartado no absurdo mundo vitoriano de Oxford e Cambridge - onde Virginia Woolf é acolhida como palestrante, mas não pode visitar as bibliotecas, a não ser acompanhada por um aluno ou professor -deu origem aos quebra-cabeças, jogos de palavras, adivinhas, charadas e portmanteau words dos livros de Alice. Para usufruir do mundo maravilhoso de Lewis Carroll, conclui-se, é necessário mergulhar de cabeça num poço profundo, com a disposição de enfrentar o inesperado.

\section{Um mergulho conceitual}

Surpresas (quase) assustadoras é a premissa básica do espetáculo idealizado por Paulo de Moraes, cujos espaços são criados pela movimentação de cortinas de tecido negro e envolvem o público na encenação.

\footnotetext{
O público se desloca de um cenário a outro como que em um labirinto, perdendo a noção de direção. A descida de um teto que obriga todos a se agacharem e cria a sensação do aumento de tamanho, espectadores vendados expostos a experiências sonoras e o deslocamento em meio a figuras imensas completam o envolvimento do público. (MACKSEN LUIZ, 1999)
}

Os trabalhos matemáticos que Charles Lutwidge Dodgson publicou em seu próprio nome não lhe renderam nem o sucesso financeiro nem a fama obtidos por seu alter ego, Lewis Carroll, embora alguns paradoxos lógicos, na área da metalógica, tivessem certo reconhecimento acadêmico. Alinha-se, portanto, ao lado da capacidade de imaginar própria de Carroll, o conhecimento matemático de Dodgson. A tendência recente em estudos da ciência cognitiva sobre funções mentais, memória, pensamento simbólico, aquisição de conhecimento e de linguagem - funções em que a mente humana mais se aproxima de um computador- é concentrar-se preferencialmente nos seus aspectos misteriosos e criativos. Em The Way We Think, Gilles Fauconnier e Mark Turner (2003) sintetizam a chamada teoria de conceptual blending (combinação conceitual) segundo a qual todo aprendizado e todo pensamento humano consistem em combinações de metáforas baseadas em experiências corporais básicas.

Um dos benefícios centrais de conceptual blending é a particularidade de permitir a 
compressão, em escala adequada para o entendimento humano, de conjuntos difusos de eventos. Fauconnier e Turner citam, como exemplo conhecido de todos, uma cerimônia de graduação. Cursar uma universidade envolve vários semestres de matrícula, frequentar aulas e palestras, concluir cursos e ir em frente em direção a outras etapas da vida. É o exemplo típico da compressão de uma gama difusa de eventos na estrutura abrangente de um evento especial: discursos com tempo limitado, homenagens, entrega de diplomas. A cerimônia de graduação mescla "ir às aulas" e "assistir àquele evento especial", comprimindo, em duas ou três horas, quatro anos ou mais da vida de estudante. Ouve-se uma pessoa de destaque em seu campo de conhecimento, especialmente escolhida pela turma; lá estão nossa família e todos os colegas, estes submetidos ao mesmo processo, que culmina em uma transição. É surpreendente observar que a cerimônia de graduação em si contém autocompressões, além de compressões dessas compressões. A imposição do grau e a entrega do diploma não ocupam mais de trinta segundos: o graduando levanta-se, sobe até o palco, vive um momento de transição que inclui um diálogo brevíssimo com a autoridade universitária e desce do palco como graduado (FAUCONNIER; TURNER, 2003, p. 30-31).

Não se trata de simples analogia entre a cerimônia de graduação e a vida pregressa do indivíduo, processo sobejamente conhecido. No raciocínio analógico padrão uma base do domínio fonte é aposta sobre o texto alvo, de modo que inferências disponíveis naquele são exportadas para este último. Podemos, então, racionalizar a respeito do alvo.

Os autores citam um segundo exemplo, o de um esquiador aprendiz, em que o mecanismo de conceptual blending é facilmente observável. Para ilustrar a ação desconhecida de movimentar-se sobre esquis, o instrutor sugere ao aprendiz que imite os movimentos de um garçom que carrega uma bandeja. Não acontece um processo analógico, pois o instrutor não sugere que o esquiador se movimente exatamente como um garçom. Para fazê-lo, o esquiador novato teria de remover os esquis e caminhar. É apenas dentro da combinação de conceitos, quando o aprendiz procura carregar mentalmente uma bandeja, enquanto tenta esquiar fisicamente, que aflora o modelo apropriado de ação emergente. Este não é inerente nem ao ato de esquiar nem ao de carregar a bandeja, como aconteceria na transferência por analogia (FAUCONNIER; TURNER, 2003, p. 21)

Conceptual blending não é, portanto, mera manipulação ou projeção de inferências, pois leva a uma nova ação integrada genuína. Integração nesse sentido não é um traço característico de modelos para a racionalização analógica, que depende apenas do mapeamento da estrutura. Mas está certamente nos "aspectos misteriosos e criativos" da capacidade mental de Dodgson/Carroll de detectar semelhanças entre pormenores corriqueiros da experiência corporal cotidiana na criação de seus personagens, imprimindo-lhes vida e movimento: o Coelho Branco, o Chapeleiro Maluco, a Lagarta do Narguilé, o Gato que Ri, a Lebre de Março.

O mesmo acontece na construção de espaço e ambientação no livro de Carroll. A queda interminável de Alice no poço, em perseguição ao Coelho Branco, inclui reflexões resultantes da compressão de conjuntos difusos de eventos de diferentes origens: da escola"Será que ela iria cair direto através da Terra até o país daquela gente que anda de cabeça para baixo! Os antipatias[...]" (a palavra não lhe parece correta); da vida familiar - Desejaria que sua gatinha Dinah estivesse com ela para apanhar um morcego, já que não existem ratos que voem. "Mas será que gatos comem morcegos?" (CARROLL, 2013, p. 11). Conceptual blending explica o mecanismo de criação do mundo de maravilhas, em que Lewis Carroll mergulha seus personagens.

Para Fauconnier e Turner o século XX é a idade da forma e da imaginação, graças a uma série de realizações dignas de nota: a mágica dos computadores, a descoberta do código genético, a ampla aplicação do método axiomático às ciências formais e do estruturalismo às ciências sociais. 
Identidade, integração e imaginação - operações básicas, misteriosas, poderosas, complexas e quase sempre inconscientes - estão no centro dos significados mais simples. O valor da mais simples das formas está na complexa dinâmica emergente que desencadeiam na imaginação criadora da mente humana. (FAUCONNIER; TURNER, 2003, p. 18)

O mecanismo de conceptual blending guiou, com certeza, a criação das ilustrações de Alice no país das maravilhas de John Tenniel para a representação de cada um dos personagens, na famosa Cena do Chá (FIGURA 1).

Figura 1: Ilustração de John Tenniel para Alice no país das maravilhas.

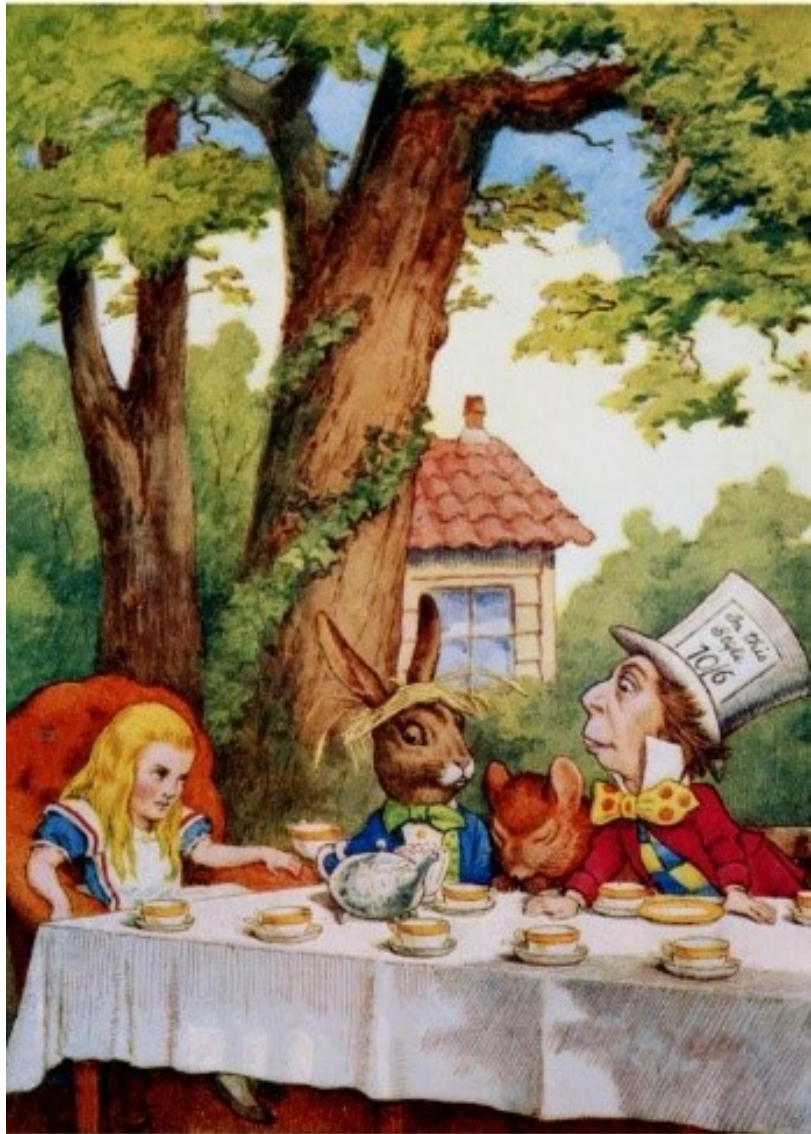

Fonte:https://www.google.com/versao-colorida-de-ilustraçao-de-john-tenniel-para-as-aventuras-de-alice-nopais-das-maravilhas.

O interminável fiveo 'clockteado país das maravilhas, além de associações próximas com o hábito nacional, leva a uma série de conexões de caráter político e econômico: o cultivo do chá na Índia, e em outros locais do Império Britânico, e as condições desiguais na exploração do açúcar e do algodão (a toalha que cobre a mesa) entre o colonizador e as populações indígenas. Por outro lado, a figura do Chapeleiro Maluco associa o conceito do traje adequado para os cavalheiros da época às normas da aristocracia britânica de se vestir com elegância para as refeições. Lembra também, no entanto, as consequências funestas para os chapeleiros da manipulação de seu material de trabalho -- o feltro ou o pelo de castor -tratado com mercúrio.

Alice, a Lebre de Março e o Chapeleiro Maluco surgem completamente transformados na adaptação do texto de Carroll para o palco, levada a efeito por Paulo de Moraes e sua equipe, bem como na posterior digitalização do espetáculo em DVD. Para dar vida às criaturas de Carroll, exigiu-se de todo o pessoal listado na ficha técnica -- diretor, 
cenógrafos e figurinistas; encarregados da dramaturgia, da preparação vocal e corporal -- e particularmente dos atores a combinação de metáforas corporais e muita imaginação para dar vida à Lagarta de Narguilé, ao Chapeleiro Maluco, às Flores Cantantes, ao Gato que Ri e à Lebre de Março. Esta última é renomeada Lebre no Cio, em consonância com a sexualização sem disfarce de alguns diálogos e movimentos corporais dos atores.

A conotação de fantasia sexual na transposição do texto de Carroll para o palco, que contraria a imagem idealizada predominante de Alice, é evidente desde as primeiras falas da Fadinha e do Duende, personagens introduzidos na encenação de Paulo de Moraes. A criação de portmanteauwordspara descrever a Alice adormecida e os movimentos sensuais dos atores insinuam a atmosfera de voluptuosidade, que vai dar o tom da encenação. Alice é "sedutora", uma "mimavera" "de nominho amadócio", "a mais bela perola de sua mamãe" "uma bambolina cheia de artimomos e artimanhas", que se acorda aos poucos, "sexpirando".

A combinação de metáforas corporais e imaginação atinge o ápice na concretização da Lagarta de Narguilé, que detém longa tradição desde as ilustrações de John Tenniel para o texto de Carroll (Figura 2), até a versão plurimidiática de Moraes (Figura 3), objeto deste estudo.

Figura 2: Alice encontra a Lagarta de Narguilé. Ilustração de John Tenniel.

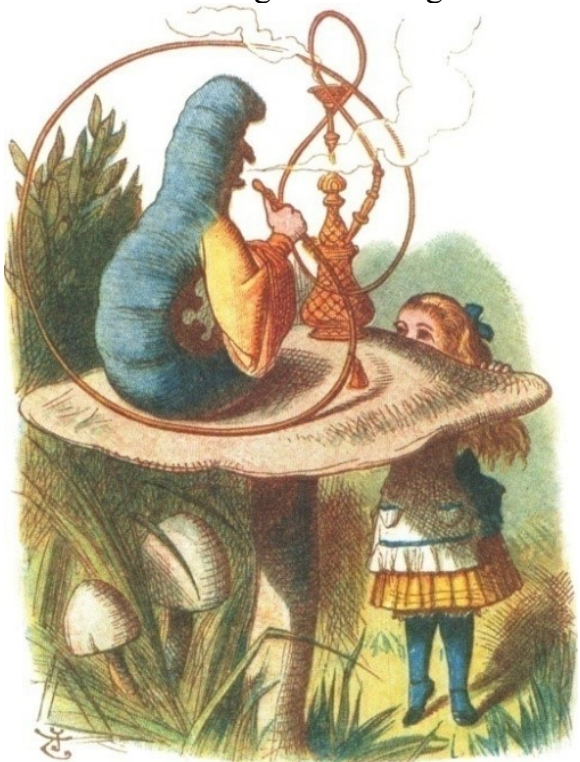

Fonte:https://www.google.com/versao-colorida-de-ilustracao-de-john-tenniel-para-as-aventuras-de-alice-nopais-das-maravilhas

Na cenografia de Gelson Amaral e Paulo Moraes para o DVD, o ator Felipe Guinnan encarna a Lagarta, usando uma vestimenta que procura reproduzir seu traço caracterizador as dezenas de patas (FIGURA 3). 


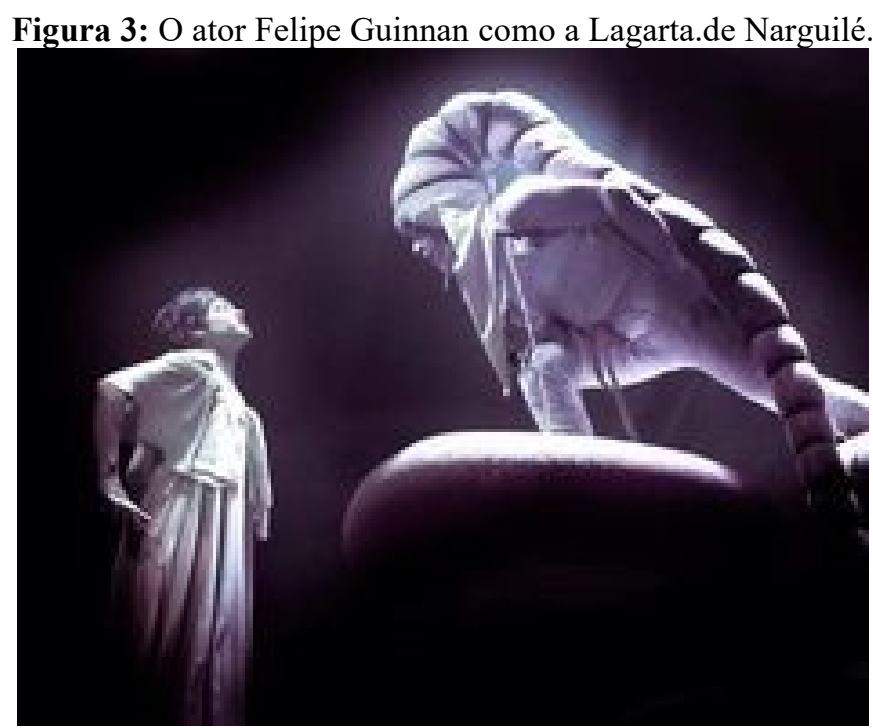

Fonte:https://www.armazemciadeteatro.com.br/repertorio/alice-atraves-do-espelho.

As primeiras adaptações intermidiáticas dos livros de Alice coincidiram praticamente com o nascimento do cinema. Alice in Wonderland, de 1903, com dezesseis cenas e duração de dez minutos, foi produzida e dirigida por Cecil Hepworth. Os recursos técnicos rudimentares não permitiram a utilização de efeitos especiais na criação dos personagens - de Alice ou das criaturas fictícias de Carroll - interpretadas por atores.

Neste particular teve especial destaque a corporificação da Lagarta de Narguilé pelo ator Ned Sparks, no filme Alice in Wonderland, da Paramount (1933). Ator criativo, conhecido pela capacidade de manter o rosto impassível e pela voz grave e rouca, Sparks viria a estabelecer modelos para a representação cênica da Lagarta. É o que se observa na animação de Walt Disney (1951) que usa efeitos visuais marcantes, mas serve-se de um ator para dar voz à criatura de Carroll: a Lagarta ilustra suas palavras soprando anéis de fumaça multicoloridos que assumem a forma de letras e objetos, mas na voz rouca e fala arrastada de Richard Haydn (GARDNER, 2013, p. 274) (Figura 4).

Figura 4: Lagarta de Narguilé, na versão da Disney (1951)

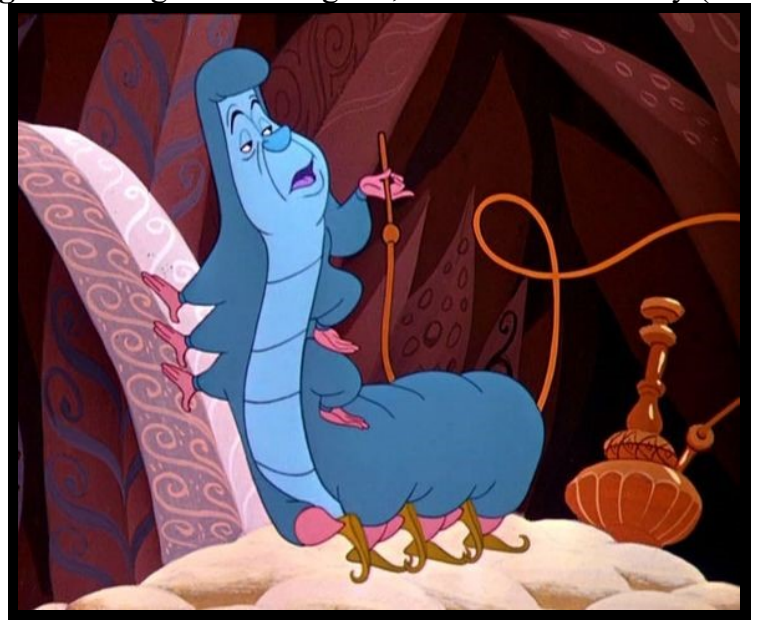

Fonte:https://www.google.com/imgres?imgurl=https $\% 3 \mathrm{~A} \% 2 \mathrm{~F} \% 2 \mathrm{Fvignette.wikia.nocookie.net} \% 2 \mathrm{Fdisneyprince}$ $\underline{\text { sas }}$

No filme Alice in Wonderland de 2010, dirigido por Tim Burton e com roteiro de Linda Woolverton, a voz de Allan Rickman adapta-se à perfeição ao discurso propositalmente monótono, que reflete a lentidão dos movimentos de Absolem, a Lagarta. 
Nossa leitura das adaptações da obra de Carroll, como resultado da combinação de metáforas corporais corriqueiras com a imaginação criadora dos seres humanos, encontra ressonância nos comentários de Valmir Santos para a Folha de São Paulo, reproduzidos na contracapa do DVD. O crítico aponta Alice através do espelho como "a melhor peça brasileira a alcançar suporte digital" e elogia a capacidade do grupo "para manejar câmeras e cortes com o risco do "ao vivo"". Destaca, finalmente, a originalidade do cenário e de stage props, na adaptação singular desse clássico "conforme manda a imaginação sem limites" de Lewis Carroll (ênfase acrescentada). Como essa, outras informações paratextuais foram indispensáveis para reconstituir a atmosfera da encenação dirigida por Paulo de Moraes, a que assistimos em Curitiba, em 1998. A digitalização em DVD oferece poucas informações peritextuais, segundo a nomenclatura de Genette para os itens incluídos no próprio corpo do texto literário, ou, neste caso, de uma gravação em vídeo. Já as informações situadas em suporte midiático externo, como artigos de jornal e entrevistas, que ele batiza de epitextuais, "na falta de um termo melhor" (GENETTE, 2009, p. 12) tiveram importância relevante para este estudo. ${ }^{1}$

O espetáculo plurimidiático de Paulo de Moraes coloca o público no lugar da protagonista, propiciando a trinta e cinco espectadores por sessão as surpresas sensoriais vividas por Alice. A experiência tem o caráter de immediacy, exigido enfaticamente pela cultura midiática de nossos dias, que deseja viver de imediato as experiências virtuais. Cabe aqui fazer referência ao conceito de remediação de Bolton e Grusin (2010), para quem nenhum evento midiático em si parece desempenhar sua tarefa cultural isolado de outras mídias. Mais ainda, a 'remediação' de mídias anteriores, que caracteriza a mídia digital de hoje não é produto de nossa época, mas está presente nos últimos séculos da representação visual no ocidente. É evidente, na transposição do texto de Carroll para a versão digitalizada em DVD, a presença dos imperativos complementares de immediacye hypermediacy, ou pluralidade de mídias. Para traduzir para um conjunto de mídias os complexos tropos dos textos de Carroll, Moraes e sua equipe valem-se de suas múltiplas habilidades para criar cenários, figurinos, animação gráfica e cenas de canto e dança, ou seja, um evento plurimidiático. Embora pareçam contraditórias, as lógicas de immediacy e hypermediacy são mutuamente dependentes. O efeito conjunto da reunião de mídias,tanto na versão digital de Alice através do espelho, como na apreciação dos livros ilustrados de Lewis Carroll, é o de mergulhar de imediato o espectador/leitor no contexto da experiência.

\section{O Espelhotáculo de Paulo de Moraes}

Em entrevista a Cintia Lopes, Paulo de Moraes fala sobre as diretrizes e objetivos da encenação itinerante de Alice através do espelho, pela Armazém Companhia de Teatro. ${ }^{2}$

\footnotetext{
Queremos falar sobre o nosso tempo. Propor questões que possam refletir o homem de hoje, suas angústias, desejos. Mas o teatro que queremos fazer também deve misturar diversão e filosofia, deve encontrar um caminho de comunicação efetivo com o público. Alice através do espelho é uma festa de teatro, uma experiência única. Não é um espetáculo, é um espelhotáculo. Permite ao público e aos atores uma grande vibração. (MORAES, 2019, s/p)
}

\footnotetext{
${ }^{1}$ Genette ilustra a importância do paratexto com uma pergunta: "Reduzidos apenas ao texto e sem o auxílio de nenhum manual, como leríamos o Ulysses de Joyce se a obra não se intitulasse Ulysses? (2009, p.10).

${ }^{2} \mathrm{O}$ espetáculo nasce em 1997 como formatura de um curso de atores em Londrina, onde trabalhavam alguns dos integrantes da companhia. Em 1998, fez temporada em um espaço alternativo construído no parque São Lourenço, em Curitiba, e se lançou nacionalmente no festival de teatro da cidade, no ano seguinte. Em seguida, estreou no Rio de Janeiro, com atores da companhia e profissionais convidados da cidade.
} 
O envolvimento do público tem início no saguão, onde o espectador recebe um copo de chá, com a sugestão de que se trata de um alucinógeno. A entrada no mundo das maravilhas se dá através do espelho, representado por uma passagem estreita que leva a um escorregador. Na cena inicial, o espectador se depara com Alice, vivida pela atriz Liliana Castro, uma bela jovem de traços delicados, profundamente adormecida sobre um divã. As explicações da mise-en-scène são dadas pelo Chapeleiro, no papel de diretor de cena (Figura $5)$.

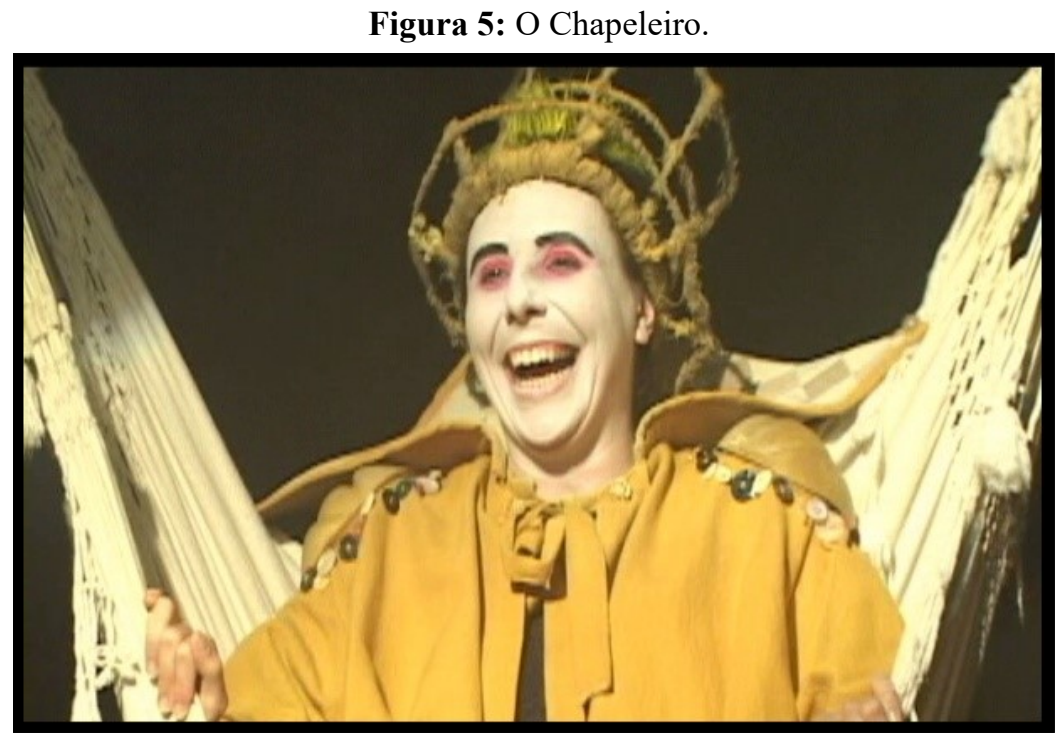

Fonte:DVD Alice através do espelho pelo grupo Armazém Companhia de Teatro (2014)

Os versos encantatórios "Cause I'm going to Strawberry Fields/Nothing is real" da canção dos Beatles acompanham o vai-e-vem do personagem numa rede, enquanto se dirige ao público:

Pessoas inteligentes sabem que não existe diferença entre o real e o irreal. Sabem que as coisas só parecem ser o que são em virtude de delicados processos mentais. Mas infelizmente essas mesmas pessoas condenam como loucura os mais engenhosos produtos da imaginação. (Transcrição do DVD)

"O real é aquilo do qual não conseguimos acordar", continua, e anuncia em voz alta: "Primeiro produto da imaginação." É a deixa para a entrada de Dodgson, um rapaz elegante que, como um príncipe encantado, desperta Alice com um beijo. O detour para o mundo dos contos de fada ameniza a atmosfera de sensualidade criada pela Fadinha e pelo Duende. Como um mestre benevolente, Dodgson instrui Alice nas inversões produzidas pelo espelho.

"O segundo produto da imaginação", anunciado pelo Chapeleiro, reconduz Alice para o mergulho no mundo das maravilhas de Carroll. No paralelismo com a queda na toca do Coelho Branco, o espectador experimenta em um escorregador as sensações contraditórias da personagem, misto de curiosidade, espanto e medo. Em termos técnicos é certamente mais fácil reproduzir os efeitos da precipitação em um fosso profundo, do que a travessia física do espelho. A animação gráfica representando um corpo que cai contribui para criar no público a sensação da queda involuntária e abrupta. Um fac-símile da protagonista,logo substituído pelo corpo presente da atriz, situa Alice no ponto final de sua queda no desconhecido.

O público se desloca de um espaço cênico para outro, criados pela movimentação de cortinas pretas, como se estivesse em um labirinto, perdendo a noção de direção. Partilha, portanto, da confusão de Alice após o impacto da queda, que se traduz na ânsia de sair daquele lugar: "Vou fechar os olhos e vou sair daqui," arrisca Alice. Bebe, então, o conteúdo de um frasco rotulado "Beba-me" e diminui de tamanho. "Vou acabar desaparecendo como 
uma vela", exclama angustiada. Mas, crescer subitamente, a ponto de bater a cabeça no teto, quando mastiga algumas folhas, não a deixa feliz: "Grande, grande, grande -- quero parar de crescer. Não quero virar uma velha. Não quero morrer, eu quero parar de crescer."

A sensação de aumento ou diminuição de tamanho é partilhada pelo público: o teto recua ou ameaça desabar, obrigando todos a se agacharem. Espectadores vendados expostos a experiências sonoras, outros revistados para localizar objetos desaparecidos - embora ainda fora da cena, a ameaça da Rainha Vermelha já se faz sentir -completam o envolvimento do público.

"Como é que fui me meter numa história dessas?" pergunta-se Alice. "Sei! Alguém deve estar escrevendo um livro!" A referência à escrita do texto enfatiza a natureza metateatral da encenação, que faz de Charles Lutwidge Dodgson um personagem.

Valendo-se da liberdade do artista, o diretor imprime, ainda, à sua Alice através do espelho traços de fantasia sexual. Na construção do irreal, enfatizam Fauconnier e Turner,o ser humano faz de conta, imita, simula, cria modelos, inventa fantasias e propõe hipóteses. Nossa vida mental depende em todos os sentidos do pensamento contrafactual, cujo motor é a integração de conceitos (conceptual blending) (2003). A escolha do diretor dá corpo às ideias de alguns biógrafos que não descartam a possibilidade de que Dodgson tivesse sonhos de transformar sua amizade com Alice Lidell em um relacionamento amoroso.

Para Patrice Pavis (1998), o texto dramático só adquire significação quando encenado e não existe apenas um modo de fazê-lo. Ao contrário, as múltiplas formas de encenação possíveis "multiplicam os significados do texto, que não é mais o centro fixo da performance teatral, como se julgou durante muito tempo" (PAVIS, 1998, p. 398). As numerosas adaptações do texto de Carroll, como vimos brevemente, formam um continuum na história das encenações e versões cinematográficas dos livros de Alice. O historiador do teatro Marvin Carlson (2001) argumenta que as encenações inevitavelmente reciclam elementos das precedentes. "O teatro é uma máquina de memória e cada produção teatral conjura fantasmas das que a antecederam." Daí o título The Haunted Theatre, que dá à obra citada. As produções teatrais não existem em dependência do texto e podem por vezes até mesmo estar em oposição ao texto. É o que acontece na encenação de Moraes.

A discussão de identidade e a oferta do cogumelo mágico, que faz crescer ou diminuir, seguem até certo ponto o texto de Carroll, no diálogo de Alice com a Lagarta de Narguilé. Uma Alice ainda atordoada pela queda tenta responder à pergunta incisiva "Quem é você?" Por outro lado, cria-se o que se pode considerar novo paradigma para a performance dos estranhos seres do mundo das maravilhas: a Lagarta, ruidosa e agressiva, terá outras funções em cenas subsequentes; os recursos circenses atingem o clímax com a entrada do Gato que Ri, executando malabarismos no trapézio.

Para demonstrar como expressa prazer, o Gato que Ri ronrona, esfregando-se sensualmente nas pernas da protagonista. Suas informações sobre o caminho a seguir nada definem: o caminho depende de onde se quer chegar, para um lado a Lebre no Cio; para o outro a casa do Chapéu. Tanto faz porque ambos são loucos, como a própria Alice que, se não fosse louca, não teria vindo parar ali. Retoma-se o tema da loucura, anunciado pelo Chapeleiro na cena inicial: "Mesmo as pessoas mais esclarecidas condenam como loucura os mais engenhosos produtos da imaginação."

O roteiro de Moraes mantém excepcionalmente o diálogo entre Alice e o Gato de Cheshire $^{3}$ do livro de Carroll, quando a protagonista indaga que espécie de gente vive por ali.O Gato acena com a pata direita e depois com a esquerda para indicar onde vivem os personagens.

\footnotetext{
${ }^{3}$ Pesquisadores atribuem a origem do nome a um queijo da região moldado na forma de um gato. Convém lembrar que Lewis Carroll era nascido em Cheshire, o que seria uma explicação mais coerente. (GARDNER, in CARROLL, 2013, p. 277).
} 


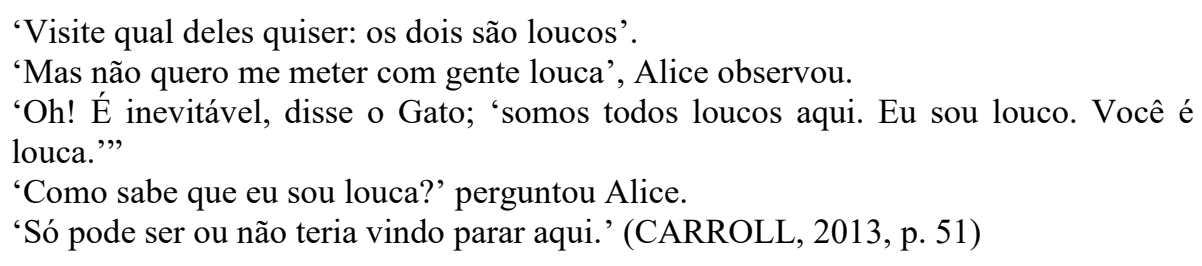

Em outras palavras, o mundo em que vivemos é tão maluco que só mesmo a lógica dos sonhos, onde transcorre a aventura de Alice, consegue representá-lo. É coerente com a temática da loucura a cena seguinte, em que a imaginação engenhosa dos encenadores coloca todo o elenco em uma enfermaria de alienados, vestidos com roupas de dormir e toucas brancas. Sob a regência da Lagarta, cantam em coro "Let's go to the Wonderland, Aleluia" e encenam a corrida maluca.

A cena seguinte, a famosa Cena do Chá, contrasta violentamente com a versão circunspecta de Tenniel (Figura 3), em que a tímida Lebre de Março e o solene Chapeleiro entretêm a menina Alice. A renomeada Lebre no Cio veste trajes sumários de cor vermelha e estala um chicotinho, em atitudes lúbricas. A sexualidade explícita da versão de Paulo de Moraes traz à baila a controvérsia entre biógrafos, críticos e historiadores da literatura sobre "o principal hobby de Lewis Carroll - aquele que lhe proporcionou as maiores alegrias divertir menininhas" (GARDNER, in CARROLL, 2013, p. xii).

Carroll tornou-se conhecido por suas fotos artísticas da cena vitoriana. Quando a oportunidade se apresentava, acrescenta Gardner, desenhava ou fotografava os corpos nus de meninas (em contraste com os dos meninos, por quem professava horror), "com a permissão da mãe, é claro" (GARDNER, 2013, p. xii).Havia uma tendência na Inglaterra vitoriana, refletida na literatura da época, a idealizar a beleza e a pureza virginal das meninas". Estaria Carroll convencido de que "sua inclinação se situava num elevado nível espiritual?" (id.p. xiv).

“O que você fazia com menininhas?” é a acusação da desalmada Rainha Vermelha, na cena exponencial do julgamento de Charles Lutwidge Dodgson, o Criador como réu, à mercê de suas criaturas.

\section{O julgamento do criador por suas criaturas}

No clímax do espelhotáculo de Paulo de Moraes surgem elementos novos que podem determinar a resolução dos conflitos. Alice é chamada a testemunhar e faz protestos apaixonados para salvar seu amado Dodô da sentença de morte, "Cortem-lhe a cabeça", pronunciada pela Rainha Vermelha, antes mesmo de se chegar a um veredicto.

Aplica-se aqui a particularidade do principio de conceptual blending de permitir a compressão de conjuntos difusos de eventos para facilitar o entendimento humano. Além disso, uma das forças da combinação conceitual é a de carregar em si o germe de toda uma rede (network) de significados. Se essa rede está ativa em sua totalidade, a combinação em si traz inferências e consequências para o restante da rede. Entretanto, se a rede ainda não foi construída em sua totalidade, ou foi esquecida em parte, ou, ainda, se porções relevantes dessa rede não estão ativas no momento de pensar, a combinação de conceitos tem o papel importante de estimular tais ativações (FAUCONNIER; TURNER, 2003, p. 333-339).

A combinação conceitual pode funcionar como recurso mnemônico, ou como gatilho portador de pequenas compressões que nos levam a compreender partes mais extensas da rede. As pessoas na assistência, que têm conhecimento das controvérsias sobre o comportamento de Charles Lutwidge Dodgson e sobre sua persona Lewis Carroll, podem compreender de imediato as falas dos membros do tribunal - o Rei de Copas, a Tartaruga do 
Narguilé, o Gato que $\mathrm{Ri}$ e a impiedosa Rainha Vermelha; outras serão lembradas possivelmente de associações anteriores entra a obra de Carroll e acontecimentos de sua própria vida.

Funcionam como gatilho para o restante da plateia certas incongruências no espaço físico da combinação conceitual, neste caso, o palco: a leitura de cartas de Carroll dirigidas a Dodgson, sugestivas de sua dupla identidade, e, particularmente a retirada física do personagem em uma cama de hospital, empurrada por um dos "enfermeiros" do asilo de loucos.

O traço distintivo da encenação de Paulo de Moraes é a priorização do foco sobre um protagonista ausente da obra escrita de Carroll e, talvez, de todas as adaptações anteriores, o criador original de todo um universo plurimidiático, que já atingiu um século e meio de existência, Charles Lutwidge Dodgson. A escolha do foco sobre Dodgson permite a concretização da proposta do diretor de apresentar questões que reflitam o homem de hoje, suas angústias e desejos, e de oferecer filosofia associada à diversão.

Como membro da plateia, apontaria limitações no espetáculo em si: apelo excessivo à experiência sensorial e à sexualidade e o volume vocal exagerado da interpretação. Por outro lado, a encenação oferece combinações de conceitos que completam uma rede específica de conhecimentos que permitem a compreensão da complexidade do texto teatral elaborado. É o caso da estrutura circular da encenação, que se inicia e conclui com a fala do Chapeleiro sobre as fronteiras permeáveis entre o real e o irreal, e sobre a condenação como loucura "dos mais engenhosos produtos da imaginação".

\section{Referências}

Alice através do espelho. Direção de Paulo de Moraes. BRA: Armazém Companhia de Teatro. Petrobrás. 1 DVD (70 min).

Bolter, J. D.; Grusin, R. Remediation. Understanding New Media. Cambridge, Mass.: MIT Press, 2002.

Carlson, M. The Haunted Stage: the Theatre as Memory Machine. Michigan: The University of Michigan Press, 2001.

Carroll, L. Alice. Edição comentada e ilustrada. Aventuras de Alice no país das maravilhas e Através do espelho. Ilustrações originais de John Tenniel. Introdução e notas de Martin Gardner. Tradução de Maria Luiza X. de A. Borges. 2.ed. Rio de Janeiro: Zahar, 2013.

Corso, D.L.; Corso, M. A psicanálise na Terra do Nunca: Ensaios sobre a fantasia. Porto Alegre: Penso, 2011.

Fauconnier, G.; Turner, M. The Way We Think: Conceptual Blending and the Mind's Hidden Complexities. New York: Basic Books, 2003.

Genette, G. Paratextos editoriais. Tradução de Álvaro Faleiros. São Paulo: Ateliê Editorial, 2009.

Macksen Luiz "Envolvimento concreto do espectador". Jornal do Brasil, Rio de Janeiro, 10 abr. 1999. Disponível em http://enciclopedia.itaucultural.org.br/pessoa399810/paulo-demoraes. Acesso em: 05 de jun. 2019. 
Paulo de Moraes. In: ENCICLOPÉDIA Itaú Cultural de Arte e Cultura Brasileiras. São Paulo: Itaú Cultural, 2019. Disponível em: http://enciclopedia.itaucultural.org.br/pessoa399810/paulo-de-moraes.Acesso em: 05 de jun. 2019.

Pavis, P. Dictionary of the Theatre: Terms, Concepts and Analysis. Trans. Christine Shantz. Toronto: Un. of Toronto Press, 1998.

Santos, W. Folha de São Paulo. Disponível em: Alice através do espelho. Direção de Paulo de Moraes. BRA: Armazém Companhia de Teatro. Petrobrás. 1 DVD (70 min).

Recebido em: 23 de agosto de 2019 Aceito em: 07 de novembro de 2019

Publicado em: Dezembro de 2019 